\title{
The Determinants of Early Initiation of Breastfeeding Practice among Mothers Attending a Tertiary Hospital, Kathmandu
}

\section{Sharada Acharya ${ }^{1}$, Chitra Khanal ${ }^{2}$, Akriti Shree Dahal ${ }^{1}$, Mankeshari Maharjan ${ }^{1}$ and Bhagawati Bhandari ${ }^{1}$}

${ }^{1}$ National Academy of Medical Sciences, Bir Hospital Nursing Campus, Gaushala, Kathmandu, Nepal

${ }^{2}$ Ministry of Health and Population, Ramshahpath, Kathmandu, Nepal

Correspondence:

Sharada Acharya

National Academy of Medical Sciences

Bir Hospital Nursing Campus, Gaushala, Kathmandu, Nepal

E-mail: saruacharyasn@gmail.com

DOI: $10.3126 /$ jnps.v39i3.24909

Submitted on: $2019-07-18$

Accepted on: 2020-05-08

Acknowledgements: None

Funding: Nil

Conflict of Interest: None declared

Permission from IRB: Yes

To cite this article: Acharya $S$, Khanal C, Dahal A, Maharjan M, Bhandari B. The determinants of early initiation of breastfeeding practice among mothers attending a tertiary hospital, Kathmandu. J Nepal Paediatr Soc. 2019;39(3):168-73.

\begin{abstract}
Introduction: Breastfeeding is the best way of providing ideal food for the optimal growth and development of an infant. Early initiation of breastfeeding (EIBF) within one hour of birth is one of the cost effective strategies to reduce neonatal mortality. The aim of the study was to find out the determinants of breastfeeding practice.
\end{abstract}

Methods: This was a descriptive cross-sectional study conducted among 207 mothers who have child from birth to 12 months in Maternal and Child Health (MCH) Clinic of tertiary care referral hospital. The mothers for the study were selected using probability sampling technique. Variables were analysed using a multivariate logistic regression model to identify the determinants of EIBF.

Results: The prevalence of EIBF in the study population was 47.3\%. Caesarean delivery (AOR: 3.449, CI: 1.224-9.719, $\mathrm{p}=$ 0.019), mothers who have done more than one postnatal visit (AOR: 2.824, CI: 1.126-7.079, $\mathrm{p}=0.027$ ) and low birth weight babies (AOR: 7.973, CI: 1.571-40.465, $\mathrm{p}=0.027$ ) were more likely to delay initiation of breastfeeding.

Conclusions: Less than half newborn receive breast milk within the first hour of birth. Mothers delivered by caesarean section, who have done more than two postnatal visit and low birth weight babies were more likely to delay initiation of breastfeeding. These are the major determinants of initiation of breastfeeding. Existing breastfeeding promotion program should be strengthened within the existing health care system.

Key words: breastfeeding; caesarean section; determinants; early initiation; infant

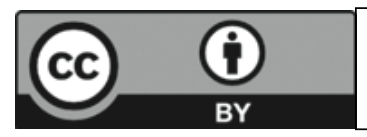

This work is licensed under creative common attribution 3.0 license 


\section{INTRODUCTION}

Appropriate breastfeeding practices are essential for the growth and development of infants. Early initiation of breastfeeding is defined as feeding mothers' breast milk to newborn infants within the first hour of birth. ${ }^{1}$ In Nepal, every year 57,000 under-five children lose their lives. Twenty-two percent of newborn deaths can be prevented through breastfeeding within the first hour of birth. ${ }^{2}$

The World Health Organisation (WHO) recommends exclusive breastfeeding for the first six months of life, followed by a timely initiation of appropriate complementary foods. ${ }^{3}$ In Nepal and in South Asia, suboptimal infant feeding practices have been associated with under nutrition, which is reflected by stunting, wasting, and mortality. ${ }^{4}$ Delayed initiation of breastfeeding continues to be a problem in Nepal as only four in 10 newborn infants receive breast milk within the first hour of birth. ${ }^{5}$

Most infants in Nepal receive colostrum but less than half initiate breastfeeding within an hour of birth and one-third are fed prelacteal feeds, which may negatively affect breastfeeding and health throughout early infancy. ${ }^{6}$ According to a systematic review, infants who initiated breastfeeding after one hour were at 33\% risk of neonatal mortality. ${ }^{7}$ Neonatal sepsis is one of the major causes of morbidity and mortality among the newborns in the developing world. ${ }^{8}$ A study from Zimbabwe showed that delayed breastfeeding increases the risk of developing neonatal sepsis within the first one week of life. ${ }^{9}$

According to Nepal Demographic Health Survey 2011, percentage that started breastfeeding within one hour of birth is very low. Similarly, percentage of babies who received pre-lacteal feed is very high in Central Terai in comparison to other ecological region and exclusively breastfed for six months of life are $70 \% .{ }^{10}$ But according to Central Bureau of Statistics (2014), infants who are exclusively breastfed for six months of life are $56.9 \%$ in 2014. ${ }^{11}$ This decreasing trend is alarming, thus the researcher wanted to find out the determinants of early initiation of breastfeeding practice.

\section{METHODS}

A cross-sectional descriptive study was carried out after getting the proposal approved by Ethical Committee of the hospital. Semi-Structured interview schedule was developed. The sampling unit was taken from maternal and child health $(\mathrm{MCH})$ clinic of the hospital. To allocate the study subjects, first the average number of clients who visit the $\mathrm{MCH}$ clinic was estimated by referring to the client registration book of same month of previous year. First mother was selected with lottery method from serial number of registration book. First number was three, and then every alternate mother was taken. A total of 207 mothers attending the $\mathrm{MCH}$ clinic with child less than one year of age were taken for the study. Data was collected for one month from February to March, 2016. The data were edited, classified, coded and entered in the Statistical Package for Social Science (SPSS) version 16 for analysis. Data were analysed by using descriptive (frequency, percentage, mean and standard deviation) and inferential statistics (chi square test and fisher exact test). Variables that were significant on the bivariate analysis at $\mathrm{p}<$ 0.05 were further analysed in multivariate logistic regression to identify the determinants of breastfeeding practice.

\section{RESULTS}

Mean age of mothers was $26.51( \pm 4.37)$ years and $45.9 \%$ of mothers belonged to Brahmin / Chhetri ethnicity. More than half $(59.9 \%)$ of the mothers were from nuclear family. More than half $(52 \%)$ of the mothers had higher secondary and graduate level education (Table 1). However most (70\%) of them were home makers. Almost all (98.9\%) mothers had done antenatal visit; $97 \%$ had done four or more ANC visits. More than half (61.6\%) of the mothers did not receive information regarding breastfeeding during ANC visit.

More than half (68.6\%) delivery was normal where as $30.9 \%$ was cesarean section. Similarly, majority (96.6\%) of the mothers had done postnatal visit (Table 3). Regarding birth weight, 91.8\% had normal birth weight and $8.17 \%$ had low birth weight. More than half $(57.5 \%)$ of the mothers were primiparous. Majority (95.2\%) of the children were born in the hospital . 
Table 1. Socio-demographic Characteristics of the Mother

\begin{tabular}{|lrr|}
\hline $\begin{array}{l}\text { Socio-demographic } \\
\text { Characteristics }\end{array}$ & Number \\
\hline $\begin{array}{l}\text { Educational status of mother } \\
\text { (n = 207) }\end{array}$ & & \\
$\quad$ Illiterate & 9 & 4.3 \\
$\quad$ Literate & 198 & 95.7 \\
If literate (n = 198) & & \\
$\quad$ Can read and write & 6 & 3 \\
$\quad$ Primary (up to 5 class) & 21 & 10.6 \\
$\quad$ Secondary (6- 10 class) & 68 & 34.3 \\
$\quad$ Higher secondary (11-12) & 58 & 29.3 \\
$\quad$ Graduate (bachelor and & 45 & 22.7 \\
& & \\
Occupation of mother & & \\
(n = 207) & & \\
$\quad$ Home maker & 145 & 70 \\
Business & 29 & 14 \\
Service & 25 & 12.1 \\
Labour & 3 & 1.4 \\
Farming & 1 & 0.5 \\
Others & 4 & 1.9
\end{tabular}

Majority (96.6\%) of the mothers were aware about exclusive breast feeding; $73.9 \%$ were also aware regarding correct time (six months) for exclusive breastfeeding (Table 3 ).

Table 4 shows that less than half $(47.3 \%)$ of the mothers initiated early breastfeeding (within first hour of delivery). Majority (94.2\%) of the mothers fed colostrum. Similarly, 20.3\% mothers had practice of prelacteal feeding. Formula milk was the most common pre-lacteal feeding (Table 4).

Multivariate logistic regression (Table 5) showed that 'mothers who had caesarean section (AOR: 3.449, CI: $1.224-9.719, \mathrm{p}=0.019)$, were less likely to initiate breastfeeding within one hour of birth. Similarly, mothers who had done more than one postnatal visit (AOR: 2.824, CI: 1.126 - 7.079, $\mathrm{p}=0.027)$ and who had low birth weight babies (AOR: 7.973, CI: $1.571-40.465, p=0.027$ ) were less likely to initiate breastfeeding within one hour of birth. Other variables, such as, mother's age, type of family, educational status of mother, occupation of mother and place of delivery did not have any
Table 2. Maternal Characteristics

\begin{tabular}{|lrr|}
\hline Maternal Characteristics & Number & $\%$ \\
\hline Parity $(\mathbf{n}=\mathbf{2 0 7})$ & 119 & 57.5 \\
Primiparous & 88 & 42.5 \\
Multiparous & &
\end{tabular}

\section{Number of living children}

$$
(\mathbf{n}=\mathbf{2 0 7})
$$

Up to 2

$196 \quad 94.7$

More than 2

$11 \quad 5.3$

Mean \pm SD

$1.49 \pm .630$

Birth spacing $(\mathbf{n}=\mathbf{8 8})$

Less than 24 months

More than 24 months

$1 \quad 1.1$

$87 \quad 98.9$

Antenatal visit $(\mathrm{n}=\mathbf{2 0 7})$

Yes

$203 \quad 98.1$

No

$4 \quad 1.9$

Number of antenatal visit

$(\mathrm{n}=\mathbf{2 0 3})$

Up to 3 times

$6 \quad 3$

4 times or more

$197 \quad 97$

Mean

$4.79 \pm 0.571$

Breastfeeding information

during antenatal visit $(n=203)$

Yes

No

Place of delivery $(n=207)$

Hospital

$197 \quad 95.2$

Home

$10 \quad 4.8$

Type of delivery $(n=207)$

Normal

$142 \quad 68.6$

Cesarean

Instrumental

$\begin{array}{ll}64 & 30.9\end{array}$

Postnatal visit $(n=207)$

Yes

10.5

No

$200 \quad 96.6$

$\begin{array}{ll}7 & 3.4\end{array}$

No. of postnatal visit $(n=200)$

$\begin{array}{lrr}\text { One } & 106 & 53 \\ \text { Two } & 29 & 14.5 \\ \text { Three or more } & 65 & 32.5\end{array}$

Mean

$1.80 \pm .904$

significant association with early initiation of breastfeeding.

\section{DISCUSSION}

The main objective of this study was to identify the determinants of early initiation of breastfeeding practice in tertiary level paediatric hospital in 
Table 3. Awareness of Mothers- Breastfeeding, source of information, predominant feeding, duration of exclusive breastfeeding

\begin{tabular}{|c|c|c|}
\hline Awareness of Mothers & Number & $\%$ \\
\hline \multicolumn{3}{|c|}{$\begin{array}{l}\text { Awareness regarding breastfeeding } \\
(\mathrm{n}=\mathbf{2 0 7})\end{array}$} \\
\hline Yes & 200 & 96.6 \\
\hline No & 7 & 3.4 \\
\hline \multicolumn{3}{|l|}{ Sources of information $(n=200)$} \\
\hline Health professionals & 165 & 82.5 \\
\hline $\begin{array}{l}\text { Female Community Health } \\
\text { Volunteers (FCHV) }\end{array}$ & 7 & 3.5 \\
\hline Family / Relatives / Peers & 15 & 7.5 \\
\hline Media & 43 & 21.5 \\
\hline Self (study in course) & 55 & 27.5 \\
\hline \multicolumn{3}{|c|}{$\begin{array}{l}\text { Baby need water with breastfeeding } \\
\text { till six months after birth }(n=207)\end{array}$} \\
\hline No & 163 & 78.7 \\
\hline Yes & 44 & 21.3 \\
\hline \multicolumn{3}{|c|}{$\begin{array}{l}\text { Duration of exclusive breastfeeding } \\
(n=207)\end{array}$} \\
\hline One month & 1 & 0.5 \\
\hline Three months & 8 & 3.9 \\
\hline Four months & 6 & 3 \\
\hline Five months & 37 & 18.2 \\
\hline Six months & 150 & 73.9 \\
\hline Seven months & 1 & 0.5 \\
\hline
\end{tabular}

Nepal. This study revealed that early initiation of breastfeeding (within the first hour of birth) was $47.3 \%$ which was comparable to the Nepal Demographic and health survey 2011(45\%), but lower than the report of Nepal Demographic and health survey 2016 (55\%). ${ }^{10,12}$ Study finding is higher than reported of India (32\%) and Nigeria (34.7\%) but lower than Sri Lanka (83.3\%). ${ }^{6,13,14}$ Within Nepal, the prevalence of EIBF is lower than that of Pokhara (72.2\%). ${ }^{15}$ Such variation in the rates of early initiation of breast feeding within Nepal and outside is likely due to differences in the geography, ethnicity, culture and socioeconomic status of mother. This study revealed that $94.2 \%$ of babies were given colostrum. Similar finding was reported in the study of Bhaktapur, where $91 \%$ of infants were given colostrum. ${ }^{16}$

In this study, there was no significant association between maternal age, type of family, economic status, education and occupation of mother with
Table 4. Breastfeeding practice of the mothers

\begin{tabular}{|lrr|}
\hline Breastfeeding practice & Number & $\%$ \\
\hline $\begin{array}{l}\text { Initiation of breastfeeding after } \\
\text { birth (n = 207) }\end{array}$ & & \\
$\quad$ Within 1 hour & 98 & 47.3 \\
After 1 hour & 109 & 52.7
\end{tabular}

Practice of colostrum feeding

(n= 207)

Yes

$195 \quad 94.2$

No

$12 \quad 5.8$

Reason for not colostrum feeding $(n=12)$

$\begin{array}{lll}\text { Cultural practice } & 6 & 50 \\ \text { Problem in breastfeeding } & 3 & 25 \\ \text { Don't know the importance } & 3 & 25\end{array}$

Practice of prelacteal feeding

$(n=207)$

Yes

$42 \quad 20.3$

No

$165 \quad 79.7$

Type of prelacteal feeding $(n=42)$

$\begin{array}{lll}\text { Glucose water } & 1 & 2.4\end{array}$

Animal milk $\quad 1 \quad 2.4$

Formula milk (lactogen) $\quad 40 \quad 95.2$

Reason for prelacteal feeding

$(n=42)$

Not sufficient milk secretion $\quad 12 \quad 28.6$

Caesarean section $\quad 25 \quad 59.5$

$\begin{array}{lll}\text { Advised from health workers } & 1 & 2.4\end{array}$

$\begin{array}{lll}\text { Maternal and child sickness } & 4 & 9.5\end{array}$

early initiation of breastfeeding. Similar finding was observed in $\mathrm{Nepal}^{17}$ which revealed that maternal age, maternal education, maternal occupation and socioeconomic status were not significantly co-related with early initiation of breastfeeding. In this study, we observed that, mother with first baby was found to be a significant cause of delay in initiation of breastfeeding ( $\mathrm{p}=$ 0.000, OR: $3.368 ; 95 \%$ CI: $1.887-6.013)$. This finding is consistent with findings from Ethiopia ${ }^{18}$ and Malawi. ${ }^{19}$ In Ethiopia, mothers with first child were more likely to delay initiation of breastfeeding to their babies (AOR: 0.59; 95\% CI: 0.35-0.99)..$^{18}$ This is due to the fact that previous breastfeeding experience was positively associated with intention and timely initiation of breastfeeding. It is known that nulliparous women generally have little to no 
Table 5. Multivariate logistic regression for determining factors of initiation of breastfeeding

\begin{tabular}{|c|c|c|c|}
\hline Characteristics & $\begin{array}{c}\text { Unadjusted } \\
\text { OR } \\
(95 \% \mathrm{CI})\end{array}$ & $\begin{array}{c}\text { Adjusted } \\
\text { OR } \\
(95 \% \text { CI })\end{array}$ & $\begin{array}{l}\text { a p- } \\
\text { value }\end{array}$ \\
\hline \multicolumn{4}{|l|}{$\begin{array}{l}\text { Type of delivery } \\
(\mathbf{n}=\mathbf{2 0 7})\end{array}$} \\
\hline Vaginal & 1 & 1 & \\
\hline Caesarean & $\begin{array}{r}7.485 \\
(3.603- \\
15.549)\end{array}$ & $\begin{array}{r}3.449 \\
(1.224- \\
9.719)\end{array}$ & $0.019 *$ \\
\hline \multicolumn{4}{|l|}{$\begin{array}{l}\text { Number of postnatal } \\
\text { visit }(n=200)\end{array}$} \\
\hline One visit & 1 & 1 & \\
\hline 2-3 visit & $\begin{array}{r}5.147 \\
(2.804- \\
9.447)\end{array}$ & $\begin{array}{r}2.824 \\
(1.126- \\
7.079)\end{array}$ & $0.027 *$ \\
\hline \multicolumn{4}{|l|}{$\begin{array}{l}\text { Birth weight } \\
(n=197)\end{array}$} \\
\hline Normal & 1 & 1 & \\
\hline Low & $\begin{array}{c}6.923 \\
(1.529- \\
31.338)\end{array}$ & $\begin{array}{r}7.973 \\
(1.571- \\
40.465)\end{array}$ & $0.012 *$ \\
\hline
\end{tabular}

knowledge of pregnancy and childbirth, which could be an important factor influencing attitudes and practices regarding breastfeeding during the first hour after birth. ${ }^{20}$

Present study revealed that mothers who had delivered their baby by caesarean section were 7.4 times more likely to delay initiating breastfeeding as compared to those who had vaginal delivery. Similarly, caesarean section is a barrier to early initiation in Ethiopia, India as well as western Nepal. ${ }^{5,17,18}$ Multiple studies have reported mode of delivery to be one of the major determinants of early initiation of breastfeeding in newborns. ${ }^{21}$ Delivery by caesarean section is associated with non-compliance of immediate breastfeeding. Caesarean section induces delay in skin to skin contact between mother and newborn due to anaesthesia as well as the fatigue associated with prolonged birth. ${ }^{13}$ This might be because mothers, who delivered their babies through caesarean section, take longer to recover from the effect of anaesthesia. Mothers might also find it difficult to achieve comfortable breastfeeding position and delay in making their first contact with their babies.

Current study showed that birth weight was significantly associated with early initiation of breastfeeding $(\mathrm{p}=0.004)$. Low birth weight babies (OR: 6.923; 95 and CI: 1.529 - 31.338) were 6.9 times more likely to initiate breastfeeding after 1 hour of birth (delay initiation) than normal birth weight babies. The finding is similar to those from western $\mathrm{Nepal}^{5}$ where low birth weight babies were less likely to be breastfed within the first hour of birth. This could be due to poor suckling capacity or associated illness among the low birth weight infants.

Present study has the strong limitation of being a single centric study and the results are based on verbal response only. However, the study has tried to give an insight into the present trend of breast feeding in central Nepal.

\section{CONCLUSIONS}

Based on the findings it can be concluded that less than half newborns receive breast milk within the first hour of birth. Mothers delivered by caesarean section, who have done more than two postnatal visit and low birth weight babies were more likely to delay initiation of breastfeeding. These are the major determinants of initiation of breastfeeding. Existing breastfeeding promotion program should be strengthened within the existing health care system such as in antenatal and vaccination clinics by encouraging early initiation of breastfeeding.

\section{REFERENCES}

1. UNICEF/IBFAN. Suggestions for CRC committee's concluding observations on infant and young child feeding [Internet]. 2016 [cited 2 May 2020].

2. UNICEF: Breastfeeding and complementary feeding [Internet]. 2015 [cited 2 March 2016]. 
3. World Health Organisation. Exclusive breastfeeding for six months best for babies everywhere [Internet]. 2011, January [cited 2 March 2020].

4. Lamichhane DK, Leem JH, Kim HC, Park MS, Lee JY, Moon SH, et al. Association of infant and young child feeding practices with undernutrition in children: evidence from the Nepal Demographic and Health Survey. Paediatr Int Child Health. 2016;36(4):260-2699. doi: 10.1080/20469047.2015.1109281

5. Khanal V, Scott J, Lee A, Karkee R, Binns C. Factors associated with Early Initiation of Breastfeeding in Western Nepal. Int. J. Environ. Res. Public Health. 2015;12(8):9562-74. DOI: 10.3390/ijerph120809562

6. Bhandari S, Thorne-Lyman A L, Shrestha B, Neupane S, Nonyane BAS, Manohar S. Determinants of infant breastfeeding practices in Nepal: a national study. Int Breastfeed J. 2019;14(14). DOI: 10.1186/s13006-019-0208-y

7. Smith ER, Hurt L, Chowdhury R, Sinha B, Fawzi W, Edmond KM, et al. Delayed breastfeeding initiation and infant survival: a systematic review and meta-analysis. PLoS ONE. 2017;12(7):0180722. DOI: 10.1371/journal.pone. 0180722

8. Stoll JB. Infections of neonatal infants. In: Kliegman MR SF, Geme WJ, SchorFN,et al ed. Nelson textbook of Paediatrics. 20 ed. London: Elsevier.; 2015

9. Mugadza G, Zvinavashe M, Gumbo FZ, Pedersen BS. Early breastfeeding initiation and incidence of neonatal sepsis in Chipinge District Zimbabwe. Int J Contemp Pediatr. 2018;5(1). DOI: 10.18203/2349-3291.ijcp20175564

10. Ministry of Health and Population (MOHP), New ERA, and ICF International Inc. Nepal Demographic and Health Survey 2011. Kathmandu, Nepal: Ministry of Health and Population, New ERA, and ICF International, Calverton, Maryland: 2012

11. Central Bureau of Statistics. Nepal Multiple Indicator Cluster Survey 2014: Key Findings. Kathmandu, Nepal: Central Bureau of Statistics and UNICEF Nepal; 2014

12. Ministry of Health and Population (MOHP), New ERA, and ICF International Inc. Nepal Demographic and Health Survey 2016. Kathmandu, Nepal: Ministry of Health and Population, New ERA, and ICF International, Calverton, Maryland: 2017

13. Berde A, Yalcin S. Determinants of early initiation of breastfeeding in Nigeria: a population-based study using the 2013 demograhic and health survey data. BMC Pregnancy Childb. 2016;16(1). DOI: 10.1186/s12884-016-0818-y

14. Senarath U, Siriwardena I, Godakandage S, Jayawickrama H, Fernando D, Dibley M. Determinants of breastfeeding practices: An analysis of the Sri Lanka Demographic and Health Survey 2006-2007. Matern Child Nutr. 2012;8(3):315-29. DOI: 10.1111/j.1740-8709.2011.00321

15. Chandrashekhar TS, Joshi HS, Binu VS, Shankar PR, Rana MS, Ramachandran. Breast-feeding initiation and determinants of exclusive breast-feeding - A Questionnaire survey in an urban population of Western Nepal. J Public Health Nurtr. 2006;10(2):192-7. DOI: 10.1017/S1368980007248475.

16. Ulak M, Chandyo R, Mellander L, Shrestha P, Strand T. Infant feeding practices in Bhaktapur, Nepal: a crosssectional, health facility based survey. Int Breastfeed J. 2012;7(1):1. DOI.org/10.1186/1746-4358-7-1

17. Nepal D, Jeeva S, Misra S, Paul V. Determinant of Early Initiation of Breastfeeding in a Tertiary Neonatal Unit. J Nepal Paediatr Soc. 2009;29(2):74-8. DOI: https://DOI.org/10.3126/jnps.v29i2.2042

18. Liben M L, Yesuf EM. Determinants of early initiation of breastfeeding in Amibara district, Northeastern Ethiopia: A community based cross-sectional study. Int Breastfeeding J. 2016;11(1). DOI: 10.1186/s13006-016-0067-8

19. Nkoka O, Ntenda PA, Kanje V, Milanzi EB, Arora A. Determinants of timely initiation of breast milk and exclusive breastfeeding in Malawi: a population-based cross-sectional study. Int Breastfeed J. 2019;14:37. DOI.org/10.1186/ s13006-019-0232-y

20. Senanayake P, O'Connor E, Ogbo FA. National and rural-urban prevalence and determinants of early initiation of breastfeeding in India. BMC Public Health. 2019;19:896. DOI: 10.1186/s12889-019-7246-7

21. John JR, Mistry SK, Kebede G, Manohar N, Arora A. Determinants of early initiation of breastfeeding in Ethiopia: a population-based study using the 2016 demographic and health survey data. BMC Pregnancy Childb. 2019;19:69. DOI.org/10.1186/s12884-019-2211-0 